\title{
Permanence for the Discrete Competition Model with Infinite Deviating Arguments
}

\author{
Baoguo Chen \\ Research Center for Science Technology and Society, Fuzhou University of International Studies and Trade, Fuzhou, \\ Fujian 350202, China
}

Correspondence should be addressed to Baoguo Chen; chenbaoguo2016@163.com

Received 11 August 2016; Accepted 25 September 2016

Academic Editor: Zhan Zhou

Copyright (C) 2016 Baoguo Chen. This is an open access article distributed under the Creative Commons Attribution License, which permits unrestricted use, distribution, and reproduction in any medium, provided the original work is properly cited.

Sufficient conditions are obtained for the permanence of the following discrete model of competition: $x_{1}(k+1)=$ $x_{1}(k) \exp \left\{r_{1}(k)\left[\left(K_{1}(k)+\alpha_{1}(k) \sum_{s=0}^{+\infty} J_{2}(s) x_{2}(k-s)\right) /\left(1+\sum_{s=0}^{+\infty} J_{2}(s) x_{2}(k-s)\right)-x_{1}\left(k-\delta_{1}(k)\right)\right]\right\} ; x_{2}(k+1)=x_{2}(k) \exp \left\{r_{2}(k)\left[\left(K_{2}(k)+\right.\right.\right.$ $\left.\left.\left.\alpha_{2}(k) \sum_{s=0}^{+\infty} J_{1}(s) x_{1}(k-s)\right) /\left(1+\sum_{s=0}^{+\infty} J_{1}(s) x_{1}(k-s)\right)-x_{2}\left(k-\delta_{2}(k)\right)\right]\right\}$, where $r_{i}, K_{i}, \alpha_{i}, J_{i}$, and $\delta_{i}, i=1,2$, are nonnegative sequences bounded above and below by positive constants, and $K_{i}>\alpha_{i}, i=1,2$.

\section{Introduction}

Throughout this paper, for any bounded sequence $\{h(n)\}$, set $h^{u}=\sup _{n \in N}\{h(n)\}$ and $h^{l}=\inf _{n \in N}\{h(n)\}$.

$\mathrm{Li}$ and $\mathrm{Xu}$ [1] studied the following two-species integrodifferential model of mutualism:

$$
\begin{aligned}
& N_{1}^{\prime}(t)=r_{1}(t) N_{1}(t) \\
& \cdot\left[\frac{K_{1}(t)+\alpha_{1}(t) \int_{0}^{\infty} J_{2}(s) N_{2}(t-s) d s}{1+\int_{0}^{\infty} J_{2}(s) N_{2}(t-s) d s}\right. \\
& \left.-N_{1}\left(t-\sigma_{1}(t)\right)\right], \\
& N_{2}^{\prime}(t)=r_{2}(t) N_{2}(t) \\
& \cdot\left[\frac{K_{2}(t)+\alpha_{2}(t) \int_{0}^{\infty} J_{1}(s) N_{1}(t-s) d s}{1+\int_{0}^{\infty} J_{1}(s) N_{1}(t-s) d s}\right. \\
& \left.\quad-N_{2}\left(t-\sigma_{2}(t)\right)\right] .
\end{aligned}
$$

By applying the coincidence degree theory, they showed that system (1) admits at least one positive $\omega$-periodic solution. Chen and You [2] argued that a general nonautonomous nonperiodic system is more appropriate, and for the general nonautonomous case, they showed that the system is permanent. For more background and biological adjustments of system (1), one could refer to [1-6] and the references cited therein. For more work on mutualism model, one could refer to [7-34] and the references cited therein.

$\mathrm{Li}$ and Yang [31] and $\mathrm{Li}$ [32] argued that the discrete time models governed by difference equations are more appropriate than the continuous ones when the populations have nonoverlapping generations; corresponding to system (1), they proposed the following two-species discrete model of mutualism with infinite deviating arguments:

$$
\begin{aligned}
& x_{1}(k+1)=x_{1}(k) \exp \left\{r_{1}(k)\right. \\
& \cdot\left[\frac{K_{1}(k)+\alpha_{1}(k) \sum_{s=0}^{+\infty} J_{2}(s) x_{2}(k-s)}{1+\sum_{s=0}^{+\infty} J_{2}(s) x_{2}(k-s)}\right. \\
& \left.\left.\quad-x_{1}\left(k-\delta_{1}(k)\right)\right]\right\},
\end{aligned}
$$




$$
\begin{aligned}
& x_{2}(k+1)=x_{2}(k) \exp \left\{r_{2}(k)\right. \\
& \cdot\left[\frac{K_{2}(k)+\alpha_{2}(k) \sum_{s=0}^{+\infty} J_{1}(s) x_{1}(k-s)}{1+\sum_{s=0}^{+\infty} J_{1}(s) x_{1}(k-s)}\right. \\
& \left.\left.-x_{2}\left(k-\delta_{2}(k)\right)\right]\right\},
\end{aligned}
$$

where $x_{i}(k), i=1,2$, is the density of mutualism species $i$ at the $k$ th generation; $\left\{r_{i}(k)\right\},\left\{K_{i}(k)\right\},\left\{\alpha_{i}(k)\right\},\left\{J_{i}(k)\right\}$, and $\left\{\delta_{i}(k)\right\}, i=1,2$, are bounded nonnegative sequences such that

$$
\begin{aligned}
& 0<r_{i}^{l} \leq r_{i}^{u}, \\
& 0<a_{i}^{l} \leq a_{i}^{u}, \\
& 0<K_{i}^{l} \leq K_{i}^{u}, \\
& 0<\delta_{i}^{l} \leq \delta_{i}^{u}, \\
& \sum_{j=1}^{+\infty} J_{i}(n)=1, \\
& \alpha_{i}>K_{i} .
\end{aligned}
$$

They showed that, under the above assumption, system (2) is permanent.

It brings to our attention the fact that the main results of $[31,32]$ deeply depend on the assumption $\alpha_{i}>K_{i}, i=1,2$. Now, an interesting issue is proposed: is it possible for us to investigate the persistent property of system (2) under the assumption $K_{i}>\alpha_{i}, i=1,2$ ?

From the point of view of biology, in the sequel, we shall consider (2) together with the initial conditions:

$$
x_{i}(s)=\phi_{i}(s) \text {, }
$$

$$
s=\ldots,-k,-k+1, \ldots,-2,-1, i=1,2 .
$$

Then system (2) has a unique positive solution $\left(x_{1}(k)\right.$, $\left.x_{2}(k)\right)_{k=0}^{+\infty}$ satisfying the initial condition (4).

From now on, we assume that the coefficients of system (2) satisfy the following.

(A) $\left\{r_{i}(k)\right\},\left\{K_{i}(k)\right\},\left\{\alpha_{i}(k)\right\},\left\{J_{i}(k)\right\}$, and $\left\{\delta_{i}(k)\right\}, i=1,2$, are bounded nonnegative sequences such that

$$
\begin{aligned}
& 0<r_{i}^{l} \leq r_{i}^{u}, \\
& 0<a_{i}^{l} \leq a_{i}^{u}, \\
& 0<K_{i}^{l} \leq K_{i}^{u}, \\
& 0<\delta_{i}^{l} \leq \delta_{i}^{u}, \\
& \sum_{j=1}^{+\infty} J_{i}(n)=1, \\
& K_{i}>\alpha_{i} .
\end{aligned}
$$

We mention here that such an assumption implies that the relationship between two species is competition; indeed, under the assumption $(A)$, the first equation in system (1) can be rewritten as follows:

$$
\begin{aligned}
x_{1}(k+1)=x_{1}(k) \exp \left\{r_{1}(k)\right. & {\left[\frac{K_{1}(k)+\alpha_{1}(k) \sum_{s=0}^{+\infty} J_{2}(s) x_{2}(k-s)}{1+\sum_{s=0}^{+\infty} J_{2}(s) x_{2}(k-s)}\right.} \\
- & \left.\left.x_{1}\left(k-\delta_{1}(k)\right)\right]\right\}=x_{1}(k) \exp \left\{r_{1}(k)\right. \\
. & {\left.\left[\frac{K_{1}(k)\left(1+\sum_{s=0}^{+\infty} J_{2}(s) x_{2}(k-s)\right)}{1+\sum_{s=0}^{+\infty} J_{2}(s) x_{2}(k-s)}\right]\right\} } \\
- & x_{1}\left(k-\delta_{1}(k)\right) \\
- & \left.\left.\frac{\left(K_{1}(k)-\alpha_{1}(k)\right) \sum_{s=0}^{+\infty} J_{2}(s) x_{2}(k-s)}{1+\sum_{s=0}^{+\infty} J_{2}(s) x_{2}(k-s)}\right]\right\} \\
= & x_{1}(k) \exp \left\{r _ { 1 } ( k ) \left[K_{1}(k)-x_{1}\left(k-\delta_{1}(k)\right)\right.\right. \\
- & \left.\left.\frac{\left(K_{1}(k)-\alpha_{1}(k)\right) \sum_{s=0}^{+\infty} J_{2}(s) x_{2}(k-s)}{1+\sum_{s=0}^{+\infty} J_{2}(s) x_{2}(k-s)}\right]\right\}
\end{aligned}
$$

Similar to the above analysis, the second equation in system (2) can be rewritten as follows:

$$
\begin{gathered}
x_{2}(k+1)=x_{2}(k) \exp \left\{r _ { 2 } ( k ) \left[K_{2}(k)-x_{2}\left(k-\delta_{2}(k)\right)\right.\right. \\
\left.\left.-\frac{\left(K_{2}(k)-\alpha_{2}(k)\right) \sum_{s=0}^{+\infty} J_{1}(s) x_{1}(k-s)}{1+\sum_{s=0}^{+\infty} J_{1}(s) x_{1}(k-s)}\right]\right\} .
\end{gathered}
$$

From (6) and (7), one could easily see that both species have negative effect on the other species; that is, the relationship between two species is competition.

Concerned with the persistent property of systems (2) and (4), we have the following result.

Theorem 1. In addition to (A), assume further that

$$
\begin{aligned}
& r_{1}^{l} K_{1}^{l}>r_{1}^{u}\left(K_{1}^{u}-\alpha_{1}^{l}\right) \frac{M_{2}}{1+M_{2}}, \\
& r_{2}^{l} K_{2}^{l}>r_{2}^{u}\left(K_{2}^{u}-\alpha_{2}^{l}\right) \frac{M_{1}}{1+M_{1}}
\end{aligned}
$$

holds, where

$$
M_{i}=\frac{1}{r_{i}^{l}} \exp \left\{r_{i}^{u} K_{i}^{u}(\delta+1)-1\right\}, \quad i=1,2 ;
$$

then system (2) is permanent; that is, there exist positive constants $m_{i}, M_{i}, i=1,2\left(M_{i}\right.$ is defined by (9)), which are independent of the solution of system (2), such that, for any positive 
solution $\left(N_{1}(t), N_{2}(t)\right)$ of system (2) with initial condition (4), one has

$$
m_{i} \leq \liminf _{k \rightarrow+\infty} x_{i}(k) \leq \limsup _{k \rightarrow+\infty} x_{i}(k) \leq M_{i}, \quad i=1,2 .
$$

\section{Proof of the Main Result}

Now we state several lemmas which will be useful in proving our main result.

Lemma 2 (see [11]). Assume that $\{x(k)\}$ satisfies $x(k)>0$ and

$$
x(k+1) \leq x(k) \exp \{a(k)-b(k) x(k)\}
$$

for $k \in N$, where $a(k)$ and $b(k)$ are nonnegative sequences bounded above and below by positive constants. Then

$$
\limsup _{k \rightarrow+\infty} x(k) \leq \frac{1}{b^{l}} \exp \left(a^{u}-1\right)
$$

Lemma 3 (see [11]). Assume that $\{x(k)\}$ satisfies

$$
x(k+1) \geq x(k) \exp \{a(k)-b(k) x(k)\}, \quad k \geq N_{0},
$$

$\lim \sup _{k \rightarrow+\infty} x(k) \leq x^{*}$ and $x\left(N_{0}\right)>0$, where $a(k)$ and $b(k)$ are nonnegative sequences bounded above and below by positive constants and $N_{0} \in N$. Then

$$
\liminf _{k \rightarrow+\infty} x(k) \geq \min \left\{\frac{a^{l}}{b^{u}} \exp \left\{a^{l}-b^{u} x^{*}\right\}, \frac{a^{l}}{b^{u}}\right\} .
$$

Lemma 4 (see [34]). Let $x: Z \rightarrow R$ be nonnegative bounded sequences, and let $H: N \rightarrow R$ be nonnegative sequences such that $\sum_{n=0}^{\infty} H(n)=1$. Then

$$
\begin{aligned}
\liminf _{n \rightarrow+\infty} x(n) & \leq \liminf _{n \rightarrow+\infty} \sum_{s=-\infty}^{n} H(n-s) x(s) \\
& \leq \limsup _{n \rightarrow+\infty} \sum_{s=-\infty}^{n} H(n-s) x(s) \\
& \leq \limsup _{n \rightarrow+\infty} x(n) .
\end{aligned}
$$

Now we are in the position to prove the main result of this paper.

Proof of Theorem 1. Set

$$
\delta=\max \left\{\delta_{1}^{u}, \delta_{2}^{u}\right\}
$$

Let $\left(x_{1}(k), x_{2}(k)\right)$ be any positive solution of system (2) with initial condition (4). From (6), it follows that

$$
\begin{aligned}
x_{1}(k+1) & \leq x_{1}(k) \exp \left\{r_{1}(k) K_{1}(k)\right\} \\
& \leq x_{1}(k) \exp \left\{r_{1}^{u} K_{1}^{u}\right\} .
\end{aligned}
$$

By using (17), one could easily obtain that

$$
x_{1}\left(k-\delta_{1}(k)\right) \geq x_{1}(k) \exp \left\{-r_{1}^{u} K_{1}^{u} \delta\right\} .
$$

Substituting (18) into (6), it follows that

$$
\begin{aligned}
& x_{1}(k+1) \\
& \quad \leq x_{1}(k) \exp \left\{r_{1}^{u} K_{1}^{u}-r_{1}^{l} \exp \left\{-r_{1}^{u} K_{1}^{u} \delta\right\} x_{1}(k)\right\} .
\end{aligned}
$$

Thus, as a direct corollary of Lemma 2, according to (19), one has

$$
\limsup _{k \rightarrow+\infty} x_{1}(k) \leq \frac{1}{r_{1}^{l}} \exp \left\{r_{1}^{u} K_{1}^{u}(\delta+1)-1\right\} \stackrel{\text { def }}{=} M_{1}
$$

By using (7), similar to the analysis of (17)-(20), we can obtain

$$
\limsup _{k \rightarrow+\infty} x_{2}(k) \leq \frac{1}{r_{2}^{l}} \exp \left\{r_{2}^{u} K_{2}^{u}(\delta+1)-1\right\} \stackrel{\text { def }}{=} M_{2} .
$$

From (20), (21), and Lemma 4, we have

$$
\begin{aligned}
& \limsup _{k \rightarrow+\infty} \sum_{s=0}^{+\infty} J_{i}(s) x_{i}(k-s) \\
& \quad=\underset{k \rightarrow+\infty}{\lim \sup _{s=-\infty}} \sum_{s}^{k} J_{i}(k-s) x_{i}(s) \leq \underset{k \rightarrow+\infty}{\limsup } x_{i}(k) \\
& \quad \leq M_{i}, \quad i=1,2 .
\end{aligned}
$$

Condition (6) implies that, for enough small $\varepsilon>0$, inequalities

$$
\begin{aligned}
& r_{1}^{l} K_{1}^{l}>r_{1}^{u}\left(K_{1}^{u}-\alpha_{1}^{l}\right) \frac{\left(M_{2}+\varepsilon\right)}{1+\left(M_{2}+\varepsilon\right)} \\
& r_{2}^{l} K_{2}^{l}>r_{2}^{u}\left(K_{2}^{u}-\alpha_{2}^{l}\right) \frac{\left(M_{1}+\varepsilon\right)}{1+\left(M_{1}+\varepsilon\right)}
\end{aligned}
$$

hold. For above $\varepsilon>0$, from (19)-(22), it follows that there exists $N_{1}>0$ such that, for all $k>N_{1}$ and $i=1,2$,

$$
\begin{array}{r}
\sum_{s=0}^{+\infty} J_{i}(s) x_{i}(k-s)<M_{i}+\varepsilon \\
x_{i}(k)<M_{i}+\varepsilon .
\end{array}
$$

By using the fact that $e^{x} \geq 1+x, x \geq 0$, from (9), one could easily see that

$$
\begin{aligned}
M_{1} & =\frac{1}{r_{1}^{l}} \exp \left\{r_{1}^{u} K_{1}^{u}(\delta+1)-1\right\} \geq \frac{1}{r_{1}^{l}}\left(r_{1}^{u} K_{1}^{u}(\delta+1)\right) \\
& >K_{1}^{u} \geq \alpha_{1}^{l} .
\end{aligned}
$$


For $k \geq N_{1}+\delta$, from (24) and (6), we have

$$
\begin{aligned}
& x_{1}(k+1)=x_{1}(k) \exp \left\{r _ { 1 } ( k ) \left[K_{1}(k)\right.\right. \\
& -x_{1}\left(k-\delta_{1}(k)\right) \\
& \left.\left.-\frac{\left.\left.\left(K_{1}(k)-\alpha_{1}(k)\right) \sum_{s=0}^{+\infty} J_{2}(s) x_{2}(k-s)\right]\right\}}{1+\sum_{s=0}^{+\infty} J_{2}(s) x_{2}(k-s)}\right]\right\} \\
& \geq x_{1}(k) \exp \left\{r _ { 1 } ( k ) \left[K_{1}(k)-x_{1}\left(k-\delta_{1}(k)\right)\right.\right. \\
& -\frac{\left.\left.\left(K_{1}(k)-\alpha_{1}(k)\right) \sum_{s=0}^{+\infty} J_{2}(s) x_{2}(k-s)\right]\right\}}{\sum_{s=0}^{+\infty} J_{2}(s) x_{2}(k-s)} \\
& =x_{1}(k) \exp \left\{r _ { 1 } ( k ) \left[K_{1}(k)-x_{1}\left(k-\delta_{1}(k)\right)\right.\right. \\
& \left.\left.-\left(K_{1}(k)-\alpha_{1}(k)\right)\right]\right\}=x_{1}(k) \exp \left\{r _ { 1 } ( k ) \left[\alpha_{1}(k)\right.\right. \\
& \left.\left.-x_{1}\left(k-\delta_{1}(k)\right)\right]\right\} \geq x_{1}(k) \exp \left\{r_{1}^{l} \alpha_{1}^{l}-r_{1}^{u}\left(M_{1}\right.\right. \\
& +\varepsilon)\} ;
\end{aligned}
$$

we mention here that, from (25), $r_{1}^{l} \alpha_{1}^{l}-r_{1}^{u}\left(M_{1}+\varepsilon\right)<0$. By using (26), we obtain

$$
\begin{aligned}
& x_{1}\left(k-\delta_{1}(k)\right) \\
& \quad \leq x_{1}(k) \exp \left\{-\left[r_{1}^{l} \alpha_{1}^{l}-r_{1}^{u}\left(M_{1}+\varepsilon\right)\right] \delta\right\} .
\end{aligned}
$$

Substituting (27) into (4), using (24), for $k \geq N_{1}+\delta$, it follows that

$$
\begin{aligned}
& x_{1}(k+1) \geq x_{1}(k) \exp \left\{r _ { 1 } ( k ) \left[K_{1}(k)\right.\right. \\
& -x_{1}\left(k-\delta_{1}(k)\right) \\
& \left.\left.-\frac{\left.\left.\left(K_{1}(k)-\alpha_{1}(k)\right) \sum_{s=0}^{+\infty} J_{2}(s) x_{2}(k-s)\right]\right\}}{1+\sum_{s=0}^{+\infty} J_{2}(s) x_{2}(k-s)}\right]\right\} \\
& \geq x_{1}(k) \exp \left\{r_{1}^{l} K_{1}^{l}-r_{1}^{u}\right. \\
& \cdot \exp \left\{-\left[r_{1}^{l} \alpha_{1}^{l}-r_{1}^{u}\left(M_{1}+\varepsilon\right)\right] \delta\right\} x_{1}(k) \\
& \left.-\frac{\left(K_{1}^{u}-\alpha_{1}^{l}\right) \sum_{s=0}^{+\infty} J_{2}(s) x_{2}(k-s)}{1+\sum_{s=0}^{+\infty} J_{2}(s) x_{2}(k-s)}\right\} \geq x_{1}(k) \\
& \cdot \exp \left\{r_{1}^{l} K_{1}^{l}-r_{1}^{u} \exp \left\{-\left[r_{1}^{l} \alpha_{1}^{l}-r_{1}^{u}\left(M_{1}+\varepsilon\right)\right] \delta\right\}\right. \\
& \left.\cdot x_{1}(k)-\frac{r_{1}^{u}\left(K_{1}^{u}-\alpha_{1}^{l}\right)\left(M_{2}+\varepsilon\right)}{1+\left(M_{2}+\varepsilon\right)}\right\} .
\end{aligned}
$$

Thus, as a direct corollary of Lemma 3, according to (23) and (28), one has

$$
\begin{aligned}
& \liminf _{k \rightarrow+\infty} x_{1}(k) \geq \min \left\{A_{1 \varepsilon}, A_{2 \varepsilon}\right\}, \\
& A_{1 \varepsilon}=\frac{\Delta_{1}^{\varepsilon}}{r_{1}^{u}} \exp \left\{\left[r_{1}^{l} \alpha_{1}^{l}-r_{1}^{u}\left(M_{1}+\varepsilon\right)\right] \delta\right\}, \\
& A_{2 \varepsilon}=A_{1 \varepsilon} \\
& \quad \cdot \exp \left[\Delta_{1}^{\varepsilon}-r_{1}^{u} \exp \left\{-\left[r_{1}^{l} \alpha_{1}^{l}-r_{1}^{u}\left(M_{1}+\varepsilon\right)\right] \delta\right\} M_{1}\right], \\
& \Delta_{1}^{\varepsilon}=r_{1}^{l} K_{1}^{l}-\frac{r_{1}^{u}\left(K_{1}^{u}-\alpha_{1}^{l}\right)\left(M_{2}+\varepsilon\right)}{1+\left(M_{2}+\varepsilon\right)} .
\end{aligned}
$$

Letting $\varepsilon \rightarrow 0$, it follows that

$$
\liminf _{k \rightarrow+\infty} x_{1}(k) \geq \frac{1}{2} \min \left\{A_{1}, A_{2}\right\} \stackrel{\text { def }}{=} m_{1}>0,
$$

where

$$
\begin{aligned}
& A_{1}=\frac{\Delta_{1}}{r_{1}^{u}} \exp \left\{\left[r_{1}^{l} \alpha_{1}^{l}-r_{1}^{u} M_{1}\right] \delta\right\} \\
& A_{2}=A_{1} \exp \left[\Delta_{1}-r_{1}^{u} \exp \left\{-\left[r_{1}^{l} \alpha_{1}^{l}-r_{1}^{u} M_{1}\right] \delta\right\} M_{1}\right], \\
& \Delta_{1}=r_{1}^{l} K_{1}^{l}-\frac{r_{1}^{u}\left(K_{1}^{u}-\alpha_{1}^{l}\right) M_{2}}{1+M_{2}} .
\end{aligned}
$$

Similar to the analysis of (26)-(29), by applying (24), from (7), we also have

$$
\liminf _{k \rightarrow+\infty} x_{2}(k) \geq \frac{1}{2} \min \left\{B_{1}, B_{2}\right\} \stackrel{\text { def }}{=} m_{2}>0,
$$

where

$$
\begin{aligned}
& B_{1}=\frac{\Delta_{2}}{r_{2}^{u}} \exp \left\{\left[r_{2}^{l} \alpha_{2}^{l}-r_{2}^{u} M_{2}\right] \delta\right\} \\
& B_{2}=B_{1} \exp \left[\Delta_{2}-r_{2}^{u} \exp \left\{-\left[r_{2}^{l} \alpha_{2}^{l}-r_{2}^{u} M_{2}\right] \delta\right\} M_{2}\right], \\
& \Delta_{2}=r_{2}^{l} K_{2}^{l}-\frac{r_{2}^{u}\left(K_{2}^{u}-\alpha_{2}^{l}\right) M_{1}}{1+M_{1}} .
\end{aligned}
$$

(20), (21), (31), and (33) show that system (2) is permanent. The proof of the theorem is completed.

\section{Competing Interests}

The author declares that there are no competing interests regarding the publication of this paper.

\section{Acknowledgments}

This work is supported by National Social Science Foundation of China (16BKS132), Humanities and Social Science Research Project of Ministry of Education Fund (15YJA710002), and the Natural Science Foundation of Fujian Province (2015J01283). 


\section{References}

[1] Y. Li and G. Xu, "Positive periodic solutions for an integrodifferential model of mutualism," Applied Mathematics Letters, vol. 14, no. 5, pp. 525-530, 2001.

[2] F. Chen and M. You, "Permanence for an integrodifferential model of mutualism," Applied Mathematics and Computation, vol. 186, no. 1, pp. 30-34, 2007.

[3] K. Gopalsamy, Stability and Oscillations in Delay Differential Equations of Population Dynamics, vol. 74 of Mathematics and Its Applications, Kluwer Academic Publishers, Boston, Mass, USA, 1992.

[4] A. M. Dean, "A simple model of mutualism," The American Naturalist, vol. 121, no. 3, pp. 409-417, 1983.

[5] D. H. Boucher, The Biology of Mutualism, Ecology and Evolution, Croom Helm, London, UK, 1985.

[6] C. L. Wolin and L. R. Lawlor, "Models of facultatlve mutuahsm: density effects," The American Naturalist, vol.124, no. 6, pp. 843$862,1984$.

[7] F. D. Chen, X. Y. Liao, and Z. K. Huang, "The dynamic behavior of $\mathrm{N}$-species co-operation system with continuous time delays and feedback controls," Applied Mathematics and Computation, vol. 181, no. 2, pp. 803-815, 2006.

[8] R. Y. Han and F. D. Chen, "Global stability of a commensal symbiosis model with feedback controls," Communications in Mathematical Biology and Neuroscience, vol. 2015, article 15, 2015.

[9] J. Y. Xu and F. D. Chen, "Permanence of a Lotka-Volterra cooperative system with time delays and feedback controls," Communications in Mathematical Biology and Neuroscience, vol. 2015, article 18, 12 pages, 2015.

[10] F. Chen, "Permanence of a discrete $N$-species cooperation system with time delays and feedback controls," Applied Mathematics and Computation, vol. 186, no. 1, pp. 23-29, 2007.

[11] F. Chen, "Permanence for the discrete mutualism model with time delays," Mathematical and Computer Modelling, vol. 47, no. 3-4, pp. 431-435, 2008.

[12] F. Chen, J. Yang, L. Chen, and X. Xie, "On a mutualism model with feedback controls," Applied Mathematics and Computation, vol. 214, no. 2, pp. 581-587, 2009.

[13] F. D. Chen and X. D. Xie, Study on the Dynamic Behaviors of Cooperation Population Modeling, Science Press, Beijing, China, 2014.

[14] L. J. Chen, L. J. Chen, and Z. Li, "Permanence of a delayed discrete mutualism model with feedback controls," Mathematical and Computer Modelling, vol. 50, no. 7-8, pp. 1083-1089, 2009.

[15] L. Chen and X. Xie, "Permanence of and $N$-species cooperation system with continuous time delays and feedback controls," Nonlinear Analysis: Real World Applications, vol. 12, no. 1, pp. 34-38, 2011.

[16] L. Chen, X. Xie, and L. Chen, "Feedback control variables have no influence on the permanence of a discrete $N$-species cooperation system," Discrete Dynamics in Nature and Society, vol. 2009, Article ID 306425, 10 pages, 2009.

[17] X. Xie, F. Chen, and Y. Xue, "Note on the stability property of a cooperative system incorporating harvesting," Discrete Dynamics in Nature and Society, vol. 2014, Article ID 327823, 5 pages, 2014.

[18] X. Xie, F. Chen, K. Yang, and Y. Xue, "Global attractivity of an integrodifferential model of mutualism," Abstract and Applied Analysis, vol. 2014, Article ID 928726, 6 pages, 2014.
[19] X. D. Xie, Z. S. Miao, and Y. L. Xue, "Positive periodic solution of a discrete Lotka-Volterra commensal symbiosis model," Communications in Mathematical Biology and Neuroscience, vol. 2015, article 2, 2015.

[20] L. Y. Yang, X. D. Xie, and C. Q. Wu, "Periodic solution of a periodic predator-prey-mutualist system," Communications in Mathematical Biology and Neuroscience, vol. 2015, article 7, 2015.

[21] L. Y. Yang, F. D. Chen, C. Q. Wu, and X. D. Xie, "Global attractivity in an almost periodic predator-prey-mutualist system," Annals of Applied Mathematics, vol. 31, no. 1, pp. 42-53, 2016.

[22] R. Y. Han, X. D. Xie, and F. D. Chen, "Permanence and global attractivity of a discrete pollination mutualism in plantpollinator system with feed-back controls," Advances in Difference Equations, vol. 2016, article 199, 2016.

[23] Y. Xue, X. Xie, F. Chen, and R. Han, "Almost periodic solution of a discrete commensalism system," Discrete Dynamics in Nature and Society, vol. 2015, Article ID 295483, 11 pages, 2015.

[24] K. Yang, Z. S. Miao, F. D. Chen, and X. D. Xie, "Influence of single feedback control variable on an autonomous Holling-II type cooperative system," Journal of Mathematical Analysis and Applications, vol. 435, no. 1, pp. 874-888, 2016.

[25] W. Yang and X. Li, "Permanence of a discrete nonlinear $N$ species cooperation system with time delays and feedback controls," Applied Mathematics and Computation, vol. 218, no. 7, pp. 3581-3586, 2011.

[26] F. Wei and K. Wang, "Asymptotically periodic solution of $N$ species cooperation system with time delay," Nonlinear Analysis: Real World Applications, vol. 7, no. 4, pp. 591-596, 2006.

[27] K. Yang, X. Xie, and F. Chen, "Global stability of a discrete mutualism model," Abstract and Applied Analysis, vol. 2014, Article ID 709124, 7 pages, 2014.

[28] Z. S. Miao, X. D. Xie, and L. Q. Pu, "Dynamic behaviors of a periodic Lotka-Volterra commensal symbiosis model with impulsive," Communications in Mathematical Biology and Neuroscience, vol. 2015, article 3, 2015.

[29] R. X. Wu, L. Lin, and X. Y. Zhou, "A commensal symbiosis model with Holling type functional response," Journal of Mathematics and Computer Science, vol. 16, pp. 364-371, 2016.

[30] F. D. Chen, L. Q. Pu, and L. Y. Yang, "Positive periodic solution of a discrete obligate Lotka-Volterra model," Communications in Mathematical Biology and Neuroscience, vol. 2015, article 14, 2015.

[31] X. Li and W. Yang, "Permanence of a discrete model of mutualism with infinite deviating arguments," Discrete Dynamics in Nature and Society, vol. 2010, Article ID 931798, 7 pages, 2010.

[32] Z. Li, "Permanence for a discrete mutualism model with delays," Journal of Mathematical Study, vol. 43, no. 1, pp. 50-54, 2010.

[33] F. D. Chen, X. D. Xie, and X. F. Chen, "Dynamic behaviors of a stage-structured cooperation model," Communications in Mathematical Biology and Neuroscience, vol. 2015, article 4, 2015.

[34] F. Chen, "Permanence in a discrete Lotka-Volterra competition model with deviating arguments," Nonlinear Analysis: Real World Applications, vol. 9, no. 5, pp. 2150-2155, 2008. 


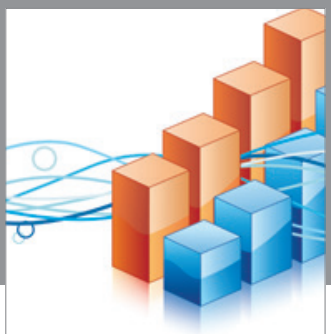

Advances in

Operations Research

vatem alat4

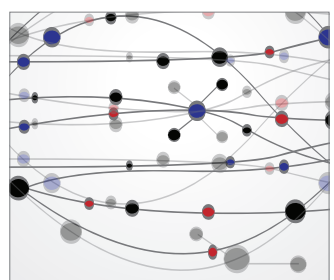

\section{The Scientific} World Journal
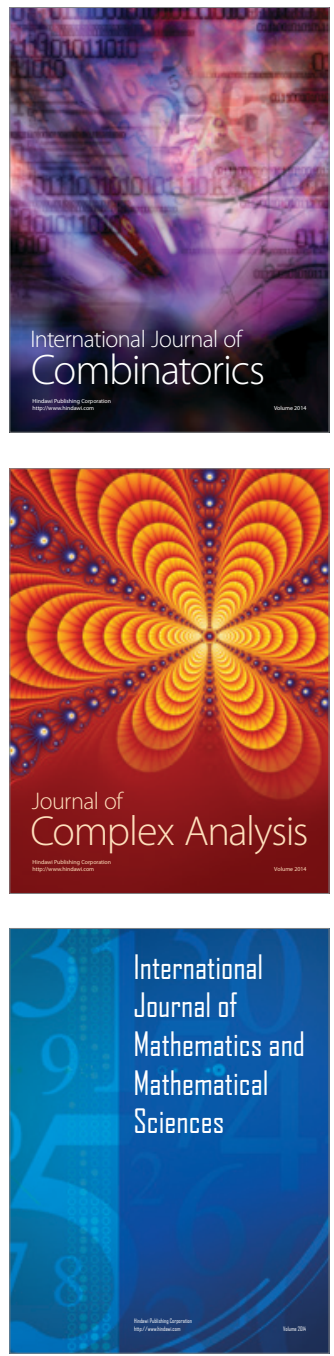
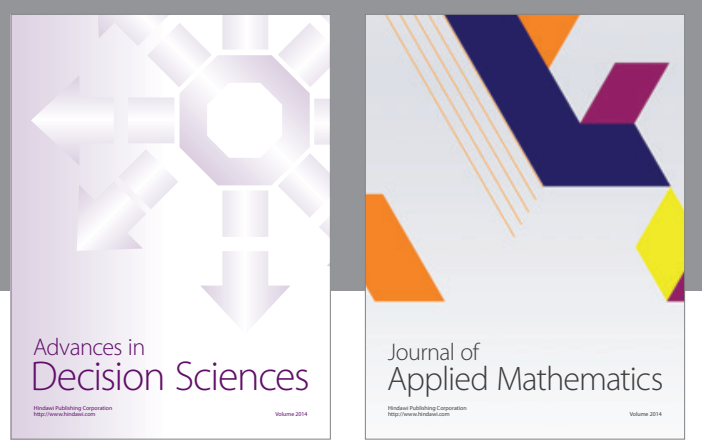

Algebra

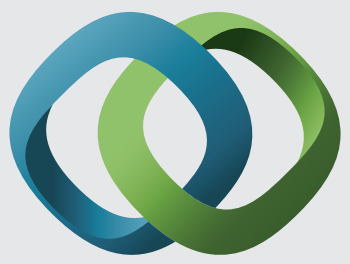

\section{Hindawi}

Submit your manuscripts at

http://www.hindawi.com
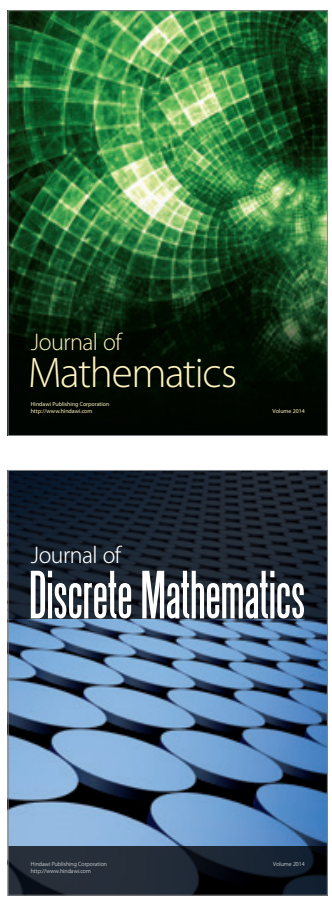

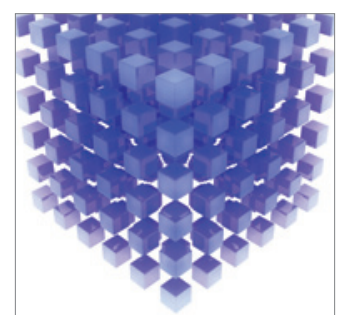

Mathematical Problems in Engineering
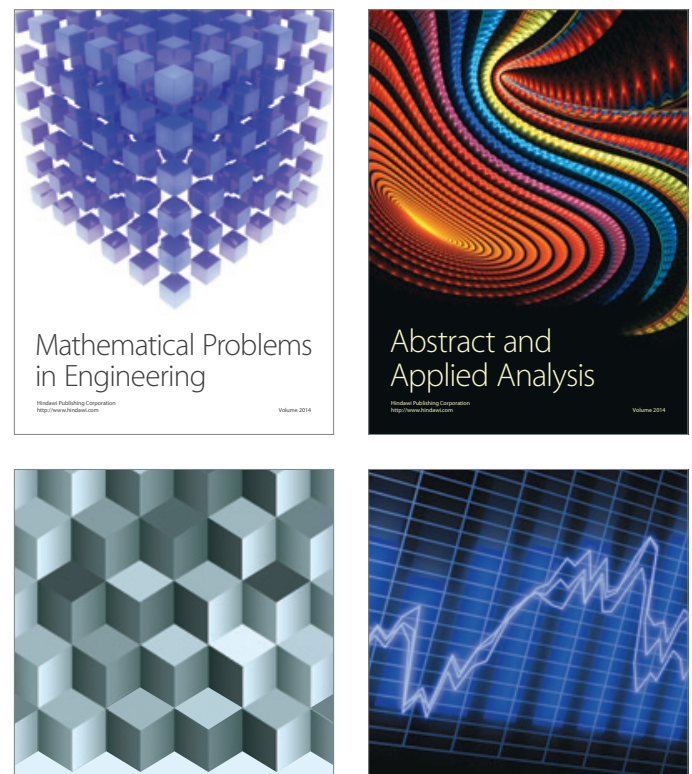

Journal of

Function Spaces

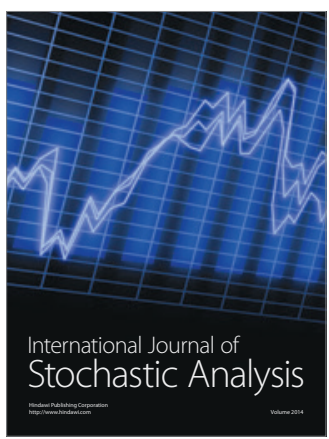

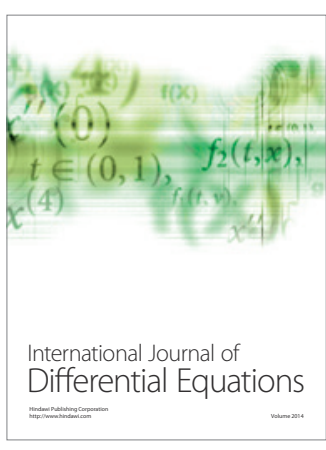
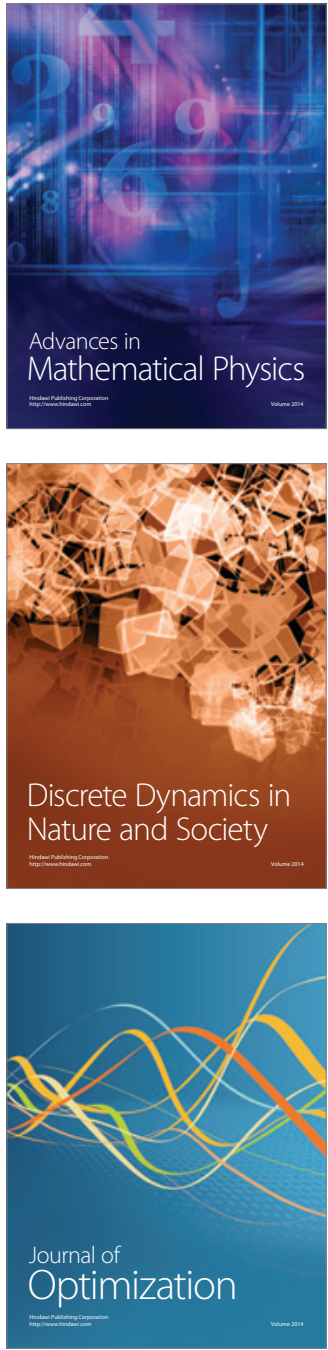